\title{
GINGIVAL ENLARGEMENT IN THALASSEMIA PATIENT — A Conjectural Association
}

\begin{abstract}
:
Thalassemia is a single gene inherited blood disease. Beta thalassemia major is life threating. It causes abnormality in various organs and oral-facial region. Thalassemia patients are immune-deficient because of iron-overload. Immune system abnormality includes neutrophilic dysfunction and impairment of phagocytosis by the monocyte-macrophage system. Iron accumulation also affects periodontal tissues, which seems to increase the level of cytokines and thus have an enhancing effect on gingival inflammation. This article highlights a peculiar case of gingival enlargement in anterior maxilla and mandible. The patient was known case of a beta-thalassemia major. Blood investigation revealed a lower level of hemoglobin. The patient underwent non-surgical periodontal therapy. Proper periodontal care improves the quality of life in these patients. This case report reinforces the significance of proper history taking with all minor details and the role of patient education in phase I therapy.
\end{abstract}

Key-words: beta-thalassemia major, blood transfusion, iron overload, gingival inflammation, non-surgical therapy.

\section{Introduction:}

Gingival enlargement is a multifactorial condition that develops as interaction between the host and the environment or in response to various stimuli. It is a common feature of gingival disease which can be caused by gingival inflammation, fibrous overgrowth or a combination of two. It may be plaque induced, associated with systemic or hormonal disturbance, as a manifestation associated with several blood dyscrasias such as leukemia, thrombocytopenia or thrombocytopathy.enlargements can lead to functional disturbances like difficulty in mastication, altered speech, esthetic and psychological problems. It can be localized or generalized or can be exaggerated or complicated by systemic diseases.

Thalassemia are inherited blood disorders characterized by decreased hemoglobin production. The term "Thalassemia or Mediterranean anemia" was coined in 1925, originating from the Greek words "Thalassa" meaning sea, and "Emia" meaning blood.

\begin{tabular}{|l|c|}
\hline \multicolumn{2}{|c|}{ Access this article online } \\
\hline \multirow{2}{*}{$\begin{array}{l}\text { Website: } \\
\text { www.ujds.in }\end{array}$} & Quick Response Code \\
\hline $\begin{array}{l}\text { DOI: } \\
\text { https://doi.org/10.21276/ujds.2020.6.3.15 }\end{array}$ \\
\hline
\end{tabular}

Clinically, TM major appears between 6 and 24 months after birth. Affected patients show developmental delay and progressively increase in pallor appearance. Along with that feeding problem, diarrhea, recurrent episodes of fever, irritability may occur. Enlargement of the abdomen can be a result of splenomegaly and hepatomegaly. Patients of TM intermedia between the age of 2 and 6 years can survive without growth and developmental retardation.TM minor patient is usually asymptomatic but has mild anemia. Hematological, $\beta$-thalassemia major is characterized by reduced hemoglobin level $(<7 \mathrm{~g} / \mathrm{dl}), \mathrm{MCH}>12$ and $<20 \mathrm{pg}$ and $\mathrm{MCV}>50$ and $<70 \mathrm{fl}$. [2]

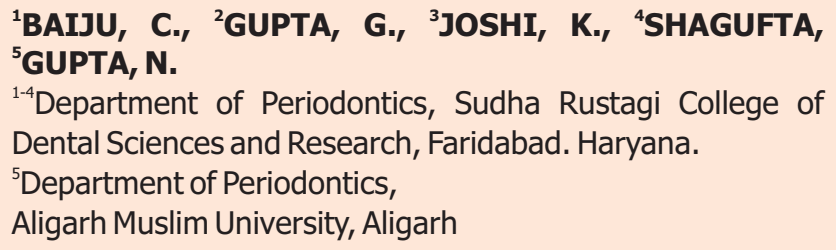

Address for Corresponding : Dr. C.S Baiju Department of periodontics, Sudha Rustagi College of Dental Sciences and Research, Faridabad.

Email :drcsbaiju@yahoo.in

Received : 24 Dec. 2020, Published : 31 Dec. 2020

How to cite this article: BAIJU, C., Gupta, G., Joshi, K., Shagufta, \& Gupta, N (2021). Gingival enlargement in thalassemia patient - A Conjectural Association. UNIVERSITY JOURNAL OF DENTAL SCIENCES, 6(3). 74 - 77 
In 1960, the most common method of treatment used for patients with thalassemia major is blood transfusion and is still being used. Due to frequent blood transfusion, the body encounters an increase in the amount of iron that can't be removed physiologically and are thus on a drug called "deferoxamine" which is an iron chelator.[3]

In dentistry prevalence and severity of the oro-facial abnormalities, dental caries experiences, and periodontal diseases in patients with thalassemia have been documented in the literature.[4] However, there was only one study reported that iron accumulation also affects periodontal tissues, which seems to increases the level of cytokines and thus has an enhancing effect on gingival inflammation.[5] this case report presents a rare combination of a thalassemic patient suffering from gingival enlargement

\section{Case History:}

A 20-year-old female patient reported to the Department of Periodontics, with the chief complaint of gingival swelling in upper and lower front teeth since one and half months. She also complained of bleeding from gums because of which she altered her oral hygiene habits and started using neem instead of a tooth brush, this resulted in an increase in the swelling of anterior segment of maxilla and mandible.

Medical history of patient revealed that she was a known case of thalassemia major and had been undergoing treatment for 15 years. ever since she was detected with thalassemia, she had been given blood transfusion two times in a month. The patient had also been prescribed Decifer (250mg/ day), Folic acid, and Calcium since the age of 5 years. Presently the systemic condition of the patient was under control she was conscious, cooperative with a normal gait and was welloriented.

\section{Intraoral examination:}

The intraoral examination revealed gingival enlargement extending from right canine to left canine region in both maxillary and mandibular arch involving buccal and lingual/palatal area. The enlargement was diffused, soft and edematous in consistency, deep red in color along with certain areas of desquamation which may have been caused due to use of neem[Fig. 1]. The periodontal probing revealed pseudo pockets in the involved area. Grade III miller's gingival recession was present in 31,41 . OHI-S and Plaque index of the patient is 2.3 and 1.2 respectively which stated fair oral hygiene of the patient. The case was classified as localized stage II, grade B periodontitis.

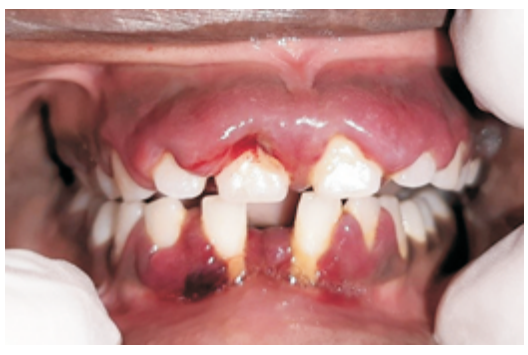

Fig 1.

\section{Hematological Examination:}

Routine hematological investigations revealed hemoglobin $7.8 \%$ and differential leucocyte count of PMN leukocytes $75 \%$, lymphocytes $23 \%$, eosinophils $2 \%$, monocytes $0 \%$ and basophils $0 \%$, platelets 1.24 after blood transfusion. As hemoglobin of patients was less than $10 \mathrm{mg} \%$ invasive treatment is not recommended.[6] Because of this reason subgingival scaling and root planing were performed in two visits.

\section{Treatment:}

The first visit of thepatients was initiated with oral hygiene instructions. She was instructed to stop using neemdatun as oral hygiene aid and was recommended a soft toothbrush. The second visit was planned immediately after blood transfusion, which included full mouth supragingival scaling. $0.2 \% \mathrm{CHX}$ was advised for 15 days in 1:1 dilution twice a day along with warm saline rinses. The patient reported after 14 days for follow up [Fig. 2], on same day subgingival scaling and root planing was performed under antibiotic coverage (2gm of amoxicillin given orally as a single dose 60 minutes before the procedure)4. The patient was further evaluated after two weeks and showed regression of the inflammation.supportive therapy was initiated which includes the reinforcement of oral hygiene instruction and oral prophylaxis every 2 months. Gingival overgrowth was treated after completion of phase I therapy [Fig. 3].

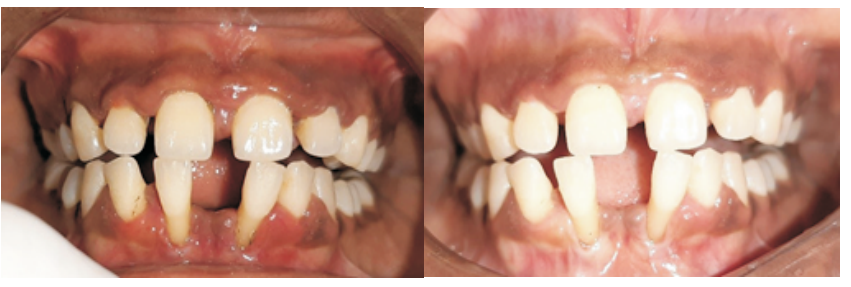

Fig. 2 


\section{Discussion:}

Thalassemia is considered to be the most common genetic disease worldwide [7] and is characterized by reduced or no synthesis of normal globin chains. The overall prevalence of thalassemia major is 3-4 \%. Beta thalassemia occurs most frequently in people of Mediterranean origin. To a lesser extent, Chinese, other Asians, and African Americans can be affected.

Oral and facial manifestation is the bossing of the skull, enlargement of the maxilla, and prominent malar eminence because of intense compensatory hyperplasia of the marrow. The expansion of the marrow cavity leads to a "Chipmunk face" facial appearance. Overdevelopment of maxilla resulted in the spacing of maxillary anterior teeth and an increase in overjet and different types of malocclusion. [8]

Thalassemia major is quite severe and fatal unless repeated blood transfusion is commenced early, due to which they are more prone to infections. Infectious complications are one of the most common cause of death in these patients. [4] Factors that are associated with these complications are eitherdiseaserelated (e.g. anemia, altered immune response and neutrophilic dysfunction because of iron overload) or treatment-related (splenectomy, transfusion-related infection and iron chelation). [9]

Thalassemia patients are immune-deficient because of iron overload which results from multiple blood transfusions, premature intramedullary erythropoiesis, increase iron absorption a compensatory reaction induced by chronic anemia. Immune system abnormality includes impairment of chemotaxis of neutrophil, decreased phagocytosis by the monocyte-macrophage system, alteration in $\mathrm{T}$ lymphocyte subsets with the enhancement of CD8 and suppression of CD4, suppression of complement system and impairment of immunoglobulin.[10] Impaired phagocytic functions are most likely contributing to impaired wound healing.[10] Research evidence indicates vitamin $\mathrm{C}$ is one of the major precipitating factors resulted due to oxidative stress induced by iron accumulation.[11] This might delay wound healing in these patients because of vitamin $C$ is required in all phases of wound healing. Deficiencies affect the maturation phase by altering collagen production. [12]

Due to iron overload, these patients have a higher risk of cardiac failure, hepatic damage, and splenomegaly, endocrine abnormalities such as diabetes mellitus, hypothyroidism, and hypoparathyroidism. Splenomegaly may be associated with the overactive spleen (Hypersplenism) a condition that can contribute to anemia in individuals with beta-thalassemia and cause low levels of WBCs, increasing the risk of infection and low levels of platelets or platelet dysfunction, which can lead to prolonged bleeding. [13]

In thalassemia, effective management of iron overload includes monitoring for both iron toxicity and the effect of excessive chelation. The chelation therapy is required to maintain safe levels of body iron, by balancing levels of its uptake after blood transfusion with levels of iron excreted after chelation therapy for which the most common drug used is deferoxamine. But, after the accumulation of iron overload removal of iron by chelation therapy become slow and is inefficient because the proportion of free iron is small at that time. Damage to tissue is often irreversible. [4] Therefore, chelation therapy should be initiated before the accumulation of toxic levels of iron.

Some recent reports stated that iron accumulation also affects periodontal tissues. One study reported that TM results in elevated levels of sRANKL, sRANKL/OPG, APRIL(a proliferation-inducing ligand), and IL-6 in serum and saliva and high levels of sRANKL, IL-6 and IL-8 in GCF as compared to systemically healthy groups. Abnormality in iron metabolism increases the production of IL- 8 and IL-6, which might be due to the overstimulation of macrophages. Not much information is available on the association of periodontal status with thalassemia patients. Susceptibility to bacterial infection is more in beta-thalassemia patients which is most likely due to impaired phagocytosis of bacteria by neutrophil.[14] Therefore, gingival inflammation seems to be enhanced in these patients due to the increased level of cytokines. Therefore, there is a need to evaluate the oral health status of the thalassemia patient.

In dentistry, thalassemia minor, major or intermedia differ in their treatment plan. Before initiation of treatment attention should be focused on the type of TM, level of hemoglobin, degree of iron overload, relative organs involved, hypersplenism and overall patient prognosis and life expectancy. Any kind of invasive procedure should be performed immediately after blood transfusion followed by antibiotic prophylaxis because these patients suffer anemia, hemolysis, and ineffective erythropoiesis. Also, TM treatments including transfusion, splenectomy, iron chelation therapy, central venous catheters further contributing to a greater risk of infection. Hemoglobin level should be more 
than $10 \mathrm{mg} \%$ before initiating any clinical procedure. [13] If blood transfusion and chelator therapy are less effective, complex surgical procedures are contraindicated.

This paper reports a case of gingival overgrowth in anterior teeth region of both arches. The patient is a known case of beta-thalassemia major. Blood investigation revealed a lower level of hemoglobin. Inflammation and enlargement, in this case, may be attributed to an increased response to plaque and compromised oral hygiene measures. Thalassemia is an aggravating factor for inflammatory cytokines. Therefore, it can be speculated that poor oral hygiene measures along with thalassemia may be a contributing factor for gingival enlargement and increased bleeding.

Etiotropic /cause-related periodontal therapy has been suggested under antibiotic prophylaxis after blood transfusion to prevent infections from both disease-related and therapy-related factors. Successful regression of inflammation was seen on follow up.

\section{Conclusion:}

There is little information about the prevalence and severity of periodontal disease with thalassemia. But, the patient's quality of life can be improved with appropriate periodontal care by preventing oral disease, masticatory difficulties and aesthetic concern, also facilitating the management of the disease by the hematologist. This case report reinforces the significance of proper history taking with all minor details and the role of patient education and motivation in phase I therapy.

\section{References:}

1. Shirzadfar H, Mokhtari N. Critical Review on Thalassemia: Types, Symptoms, and Treatment Advancements in Bioequivalence \& Bioavailability 2018; 1:15-18.

2. Renzo G, Raffaella O. Beta Thalassemia Orphanet J Rare Dis Res Treat 2010; 5:11.

3. Brittenham, GM, Patricia GM, Arthur NW, Christine ME, Young NS. Efficacy of deferoxamine in preventing complications of iron overload in patients with thalassemia major NEJM Catal 1994; 331:567-573.

4. Kumar N and Hattab FN. Dental care. In: Cappellini MD, Cohen A, Porter J, editors. Textbook of Guidelines for the management of transfusion dependent thalassaemia
(TDT), 3rd ed. Nicosia (CY): Thalassaemia International Federation; 2014.p. 178-185.

5. Caliskan U, Tonguc MO, Ciiris M, Balta N, Kirzioglu FY, Caglayan $G$ et al. The investigation of gingival iron accumulation in thalassemia major patients $\mathrm{J}$ PediatrHematolOncol 2011; 33:98-102.

6. Sakshi M, Saksham M. Dental consideration in thalassemic patients Journal of Dental and Medical Sciences 2014; 13:57-62.

7. Flint J, Harding RM, Boyce AJ, Clegg JB. The population genetics of the haemoglobinopathies BaillieresClinHaematol. 1998; 11:1-51.

8. Aydinok Y. Infections. In: Cappellini MD, Cohen A, Porter J, editors. Textbook of Guidelines for the management of transfusion dependent thalassaemia (TDT), 3rd ed. Nicosia (CY): Thalassaemia International Federation; 2014. p. 134-145.

9. Rahav G, Volach V, Shapiro M, Rund D, Rachmilewitz AE, Goldfarb A. Severe infections in thalassemic patients: prevalence and predisposing factors $\mathrm{Br} \mathrm{J}$ Haematol 2006;133:667-674.

10. Farmakis D, Giakoumis A, Polymeropoulos E, Aessopos A. Pathogenetic aspects of immune deficiency associated with $\beta$ thalassemia Med SciMonit, 2003;9:19- 22

11. De Luca C, Filosa A, Grandinetti M, Maggio F, Lamba $\mathrm{M}$, Passi S. Blood antioxidant status and urinary levels of catecholamine metabolities in beta- thalassemia Free Radic Res 1999;30:453-462.

12. Moores J. Vitamin C: a wound healing perspective $\mathrm{Br} \mathrm{J}$ Community Nurs 2013; S6:S8- 11.

13. Trinchero A, Marchetti M, Glaccherini C, Tartari C, Russo L, Falanga A. Platelet haemostatic properties in beta thalassemia : The effect of blood transfusion Blood Transfus 2017;5:413- 421.

14. Akcali A, KahramanCeneli S, Gumus P, Buduneli N, Lappin DF, Ozcaka O. The association between thalassemia major and periodontal health $\mathrm{J}$ Periodontol2015;86:1047- 1057 